\title{
Pittsburgh, Pa.
}

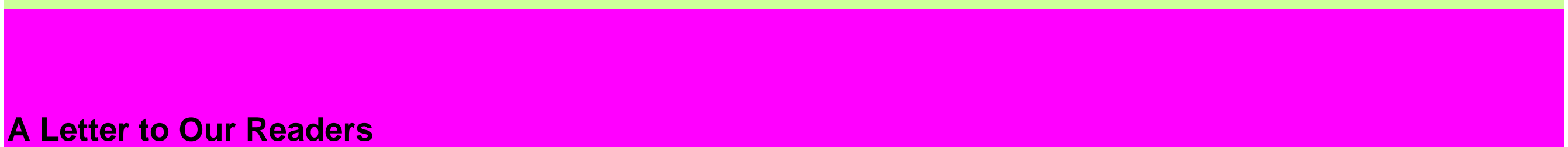

We are pleased to present this 'double-size issue' to begin our 1994 volumes. We are able to do this because of the immense support of the international community of pediat-ric neurosurgeons and their neurosci-ence colleagues. A sufficient number of manuscripts have been accepted or are under consideration to insure timely release of all eight issues planned for 1994, and perhaps additional supplements. Furthermore, the generosity and commitment of the Karger Foundation has provided support for publishing this first large issue. The blend of publisher-contributor cooperation signals real optimism for the future of|Pediatric 'Neuro-surgery. Indeed in 1995 Pediatric Neurosurgery will appear monthly, with the release of 12 issues.

The submission of increasing numbers of quality manuscripts for publication in the journal has led to the decision of the editors to refrain from publication of future meeting abstracts. The editorial board has been very active. The review process has been thoughtful and of high quality, thus also contributing to the success of the journal. The appointment of new editors promises to bring further new spirit and lively review to the editorial board.

As subscriptions continue to grow, the members of the ASPN and loyal readers are to be thanked. This conclusion is further supported by our improving rank in the science citation index.

Over the past 8 years the mission of this journal and its editorial staff has been to enhance the identity of the specialty of pediatric neurosurgery and to disseminate novel scientific and clinical information required for the care of children with diseases of the nervous system. With this first issue of 1994 we reaffirm this mission and claim to be one 